\title{
Covid-19 and Its Cultural Impact on Home Working
}

ISSN: 2576-9200

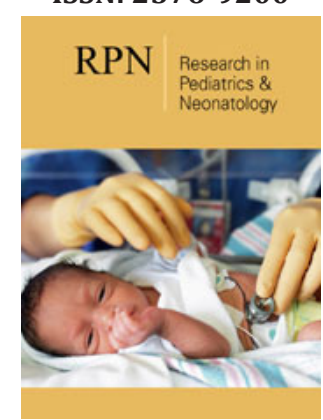

*Corresponding author: Derek Watson,Associate Professor, University of Sunderland, Faculty of Business Law \& Tourism, United Kingdom

Submission: 望 January 18, 2021

Published: 望January 25, 2021

Volume 5 - Issue 2

How to cite this article: Derek Watson. Covid-19 and Its Cultural Impact on Home Working. Research in Pediatrics \& Neonatology. 5(2). RPN. 000610. 2021. DOI: $10.31031 /$ RPN.2021.05.000610

Copyright $@$ Derek Watson. This article is distributed under the terms of the Creative Commons Attribution 4.0 International License, which permits unrestricted use and redistribution provided that the original author and source are credited.

\section{Derek Watson ${ }^{1 *}$}

${ }^{1}$ Associate Professor, University of Sunderland, Faculty of Business Law \& Tourism, United Kingdom

\section{Opinion}

Many are of the view that the Covid-19 pandemic spread like a burst pipe imposing a devastating and continuing impact. However, there was clear evidence that the lessons learnt from the Spanish flu Pandemic of 1918 were not heeded and the pandemic pipe has since systematically leaked Influenza in 1956, SARs in 2003, Swine Flu in 2009 and MERS in 2012. The antiphasis is that whilst developed economic leaders acknowledged the WHO concerns, they have done little to both avoid or prepare for the current pandemic. In direct consequence to Covid-19, approximately $38 \%$ of the UK working population were instructed to work from home. Ten months later and calls for a second national lock down in 2021, the question remains concerning the impact on home working.

The transition to working from home was radical and those affected are part of a global experiment. Twenty years after the internet, we are just starting to appreciate the benefits of working from home. The stark reality is that office space is costly and inefficient. London is the highest in the UK and globally joint second with Beijing costing around $£ 137$ per square footage. Originating as an employee-oriented HR practice home working not only reduces premises and managerial costs but in 'theory' enhances the plasticity to the challenges of work life balance. Employees have the discretion and flexibility to more readily pace their work, when to engage with colleagues to provide them with deep thought opportunities, without the daily office distractions thus reducing work related fatigue. Furthermore, the hiring of employees is no longer restricted to post codes. The corollary of home working not only diminishes the stigma of working from home but evidence suggests that with accessible social exchange, organizations are experiencing reduced staff turnover and higher productivity.

Progressive businesses such as Google and Apple have invested heavily in pioneering business models. They value a strong business culture and one which proactively encourages employees to come into work with sports facilities, wellness forums, chiefs, natural lighting, tree house meeting rooms etc. In which employees are exposed to high information and low isolation to exploit social capital so to refine their behavioural interactions such as trust and evolving team dynamics. As some of the best decisions, insights and innovation are nurtured through informal face to face chit chat in hallways, elevators, cafeterias and water fountains, all aimed at reinforcing corporal culture, fuelling productivity norms, opportunities for career progression and greater employee control over their work-life interface.

Equipped with life's office essentials, such as the internet, broadband, laptops and video chatting apps, the majority of employees were deployed into their homes often devoid of any home working predeparture awareness training. Many experienced a honeymoon period, having exchanged their daily community time and costs with perceived greater flexibility. An exception to this response were single mature and young employees who thrived and often depended upon work interactions. As reports indicate, on average, 22\% young single employees meet their partners at work. The Associated of British Foods also revealed that 
pyjama sales are increasing and both suits and personal grooming purchases have slumped, suggesting all is not well with home working and there is evidence that employee 'Reinforcement Schedules' are losing traction.

The challenge that employees are facing is that they are working in a home environment where office norms don't apply. Cats wondering across desks or siblings appearing on zoom calls demanding treats are accepted as the new cultural norm of home working. Many employees will be able to relate to the three deadly sins being the cookie jar, internet shopping and the sofa bed. Research by TELUS International attributes that such motives are often driven from a feeling of cabin fever, career stagnation, cramped home working environments, lines between personal and work life morphing together, forced childcare (data revealing that mothers are interrupted 50\% more than fathers) and strained relations. The organic repercussions have resulted in a significant increase in mental health conditions and in many cases a perception of 'Groundhog Day'.

To actively work against such symptoms is challenging and employees need to change their habit which normally takes 3 months to embed from conscious to subconscious actions. One needs to reflect on the knee jerk purchases of bicycles, weights and fit bits only to find with the passage of time that they now adopted the role of laundry hangers, dust collectors or being hidden out of sight. Having circumnavigate the rich debate on advice to stay healthy whilst working from home I have whittled down my own ten things To Do:

A. Transform to previous work schedule including breaks.

B. Convert commuting time for exercise time.

C. Dress for work, even in places which are hidden from the laptop screen.
D. Reward yourself for staying away from the three deadly sins.

E. Identify your work lair.

F. Replace emails with video app connections.

G. Focus on what you can control.

H. Do what you can with what you have got.

I. Adopt the Hedonic Tread Mill mantra.

J. Appreciate what you have and could lose.

Organizations are endeavoring to inflict agility in terms of developing or recalibrating their home working strategies. The transition, whilst underway, encounters symptomatic hinderances in terms of speed and quality which are attributable to challenges in developing esprit de corps in the pursuit of organizational cohesion and creative momentum. Organizations are well advised to encourage a 'poke the bear' culture one in which staff feel at ease in expressing their proactive views. Such an approach must guard against 'preference falsification' in which employees vocally express an opinion that is in keeping with key decision holders but are contrary to their own views. Businesses need to learn from sport in which the ratio between coaches and plays is significantly higher as they not only want to be successful but value the importance in listening to the views, suggestions and aspirations of their employees in the pursuit of paternalistic culture. To starve or ration employees of social interaction and genuine management support will reinforce feelings of isolation, corrupt team dynamics and erode employee affiliation to the corporate culture. One in which both parties will continue to struggle long after the current pandemic. 